\title{
As normas da DGS - tempo de oportunidade e responsabilidade para os médicos de família
}

Mónica Granja*

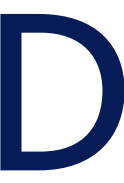

urante décadas, as normas e orientações clínicas de produção nacional emitidas pela Direcção-Geral da Saúde (DGS) e pelas sociedades científicas abrangiam áreas restritas dos cuidados de saúde e eram produzidas e actualizadas a um ritmo lento (algumas novidades anuais e ciclos de actualização de vários anos). No ano de 2011, porém, temos assistido a uma produção de normas da DGS a um ritmo crescente, totalizando 39 novas normas nos primeiros nove meses do ano e atingindo apenas no mês de Setembro o número impressionante de 23 normas emitidas. Estas normas têm incidido sobre os mais variados campos da prática clínica, inclusive sobre o seu próprio processo de elaboração.

A Ordem dos Médicos (OM) e a DGS celebraram, a 5 de Setembro passado, um protocolo de colaboração na elaboração de normas e na auditoria ao seu cumprimento. ${ }^{1}$ A OM, detendo responsabilidade oficial pela qualidade do exercício da Medicina em Portugal, tem estado arredada das orientações à prática clínica, pelo que se aguardam com expectativa sinais concretos desta colaboração.

Quase em simultâneo, a 8 de Setembro, é criada, pelo Ministério da Saúde, a Comissão Científica para as Boas Práticas Clínicas, sendo explícito no despacho que a cria a necessidade de as normas elaboradas pela DGS passarem por «mais que um patamar de validação científica». ${ }^{2}$ A esta comissão, em cuja composição se saúda a presença de quatro colegas médicos de família com reconhecido currículo académico e de investigação científica (António FariaVaz, Alberto Pinto Hespanhol, Jaime Correia de

* Médica de família, Centro de Saúde da Sra. da Hora, Unidade Local de Saúde de Matosinhos
Sousa e Vasco Maria), são atribuídas as funções de «emitir parecer científico, a pedido do director-geral da Saúde, sobre o conteúdo das orientações e normas de boa prática clínica por este elaboradas, (...) assim como sobre a sua revisão e actualização». Menos de um mês depois da criação desta comissão, boa parte das normas publicadas pela DGS vinha já por ela validada.

Nas normas publicadas no último mês é mencionado um período de audição pública, sendo formalmente convidadas a emitir parecer as sociedades científicas e estando disponível na página da DGS uma funcionalidade que permite que qualquer pessoa participe nesta audição, avaliando e sugerindo, com a devida fundamentação, a reformulação de aspectos menos correctos. A audição pública de cada norma decorre num período limitado de tempo (assinalado no início do documento) que tem oscilado entre um e dois meses após a sua publicação.

Responsáveis da DGS vieram a público frisar que estas normas não são meras orientações clínicas mas têm carácter vinculativo (prevendo-se a investigação de eventuais incumprimentos), referindo ainda que «destinam-se sobretudo aos médicos dos cuidados de saúde primários, por onde passam a maioria destes doentes». ${ }^{3}$ Sendo os médicos hospitalares também responsáveis pelo seguimento de muitos pacientes com as patologias abrangidas pelas normas e sabendo-se que parte significativa das prescrições medicamentosas dos médicos de família corresponde a renovação de prescrições iniciadas em consultas hospitalares, não se encontra justificação para esta distinção entre os médicos alvo das normas.

Por outro lado, como bem nos lembrou André Matalon, ${ }^{4}$ «guidelines não são godlines» e a existência de normas desde sempre suscitou debate entre os médicos. 
Apresentam vantagens evidentes como: poderem facilitar práticas mais correctas técnico-cientificamente; serem particularmente úteis nas especialidades mais abrangentes e aos profissionais em início de actividade; e poderem ser utilizadas pelos responsáveis técnicos e políticos como indicadores para avaliação dos profissionais. Mas as normas também apresentam perigos como: o enquadramento da prática médica numa perspectiva simplista, menorizando aspectos mais complexos e de difícil descrição ou quantificação; poderem contribuir para a burocratização do exercício; serem elaboradas por vezes com base em consensos ou em opiniões de peritos (em lugar da melhor evidência científica) ou sob influência de conflitos de interesse (individuais ou através do patrocínio de sociedades científicas); ou poderem obedecer a critérios puramente economicistas, em detrimento dos critérios clínicos que visem o bem maior do paciente.

O não cumprimento de normas por parte dos médicos pode consistir na adopção de práticas diversas das recomendadas ou na inércia clínica, termo usado para a omissão de iniciar ou intensificar essas práticas. ${ }^{5} \mathrm{O}$ mais frequente é assumir-se que os médicos que não cumprem as normas o fazem por desconhecimento, mas existem outras causas: a necessidade dos médicos atenderem às preferências dos pacientes (por exemplo quando estes pedem apenas cuidados curativos e não estão interessados na abordagem preventiva de factores de risco ou de problemas silenciosos); dúvidas sobre a aplicabilidade a pacientes concretos de normas elaboradas com base em ensaios clínicos sobre populações seleccionadas (ou apenas em estudos observacionais); ou a mera discordância quanto à sua fundamentação científica. ${ }^{6-10}$

Sendo a Medicina Geral e Familiar (MGF) tocada pela generalidade das normas que têm sido publicadas, todos os médicos de família são convocados a lê-las, a reflectir sobre elas e a discuti-las publicamente. Há indícios de que entre os médicos de família portugueses existe a massa crítica necessária ao processo de avaliação crítica e melhoria das normas da DGS. ${ }^{11}$ Saudando-se a formalização da possibilidade de participação de qualquer médico na audição pública, torna-se, porém, evidente que, se a produção inusitada de um tão elevado número de normas num tão curto espaço de tempo mal permite a respectiva tomada de conhecimento pelo seu público-alvo, muito menos permitirá, no pequeno prazo disponibilizado, o seu estudo, discussão e avaliação.
Ainda assim, para cada norma, os médicos de família têm duas opções: a sua incorporação na prática clínica, não cega e definitivamente, mas adequando-a a cada paciente e a cada situação clínica; ou a discussão sobre os seus fundamentos. E se, no contexto de produção simultânea de mais de vinte normas, os prazos avançados para a audição pública de cada norma são uma ameaça ao seu pleno aproveitamento, questionemos esses prazos ou usemos outros meios ou plataformas. Individualmente ou nas nossas comunidades de práticas (grupos de internos incluídos), nos departamentos de MGF das faculdades, no colégio de MGF da OM ou na Associação Portuguesa dos Médicos de Clínica Geral, o momento é de oportunidade, de muito trabalho e de uma imensa responsabilidade.

\section{REFERÊNCIAS BIBLIOGRÁFICAS}

1. Protocolo de cooperação entre a Direcção-Geral da Saúde e a Ordem dos Médicos. Lisboa, 2011. Disponível em: http://www.arsalgarve.minsaude.pt/site/images/centrodocs/protocolo_dgs_ordem_2011[1].pdf [acedido em 10/10/2011].

2. Ministério da Saúde. Despacho n $12422 / 2011$. Diário da República, 2. ${ }^{a}$ série - N. ${ }^{\circ} 181$ - 20 de Setembro de 2011.

3. Mendes D. DGS aperta controlo a erro de prescrição e desperdício. Diário de Notícias, 2011 Janeiro 10. Disponível em: http://www.dn.pt/inicio/portugal/interior.aspx?content_id=1753165 [acedido em 10/10/2011].

4. Oliveira A. André Matalon: Guidelines não são Godlines. Jornal Médico de Família 2010 Out 11. Disponível em:http://www.jmfamilia.com/ index.php?option=com_content\&task=view\&id=1235\&lang=pt\&ltemid=2 7 [acedido em 10/10/2011].

5. Phillips LS, Branch WT, Cook CB, Doyle JP, El-Kebbi IM, Gallina DL, et al. Clinical inertia. Ann Intern Med 2001 Nov 6; 135 (9): 825-34.

6. Francke AL, Smit MC, de Veer AJ, Mistiaen P. Factors influencing the implementation of clinical guidelines for health care professionals: a systematic meta-review. BMC Med Inform Decis Mak 2008 Sep 12; 8: 38.

7. Freeman AC, Sweeney K. Why general practitioners do not implement evidence: qualitative study. BMJ 2001 Nov 10; 323 (7321): 1000-2.

8. Van Steenkiste B, van der Weijden T, Stoffers HE, Grol R. Barriers to implement CV risk tables in routine general practice. Scand J Prim Health Care 2004 Mar; 22 (1): 32-7.

9. Berg M. Problems and promises of the protocol. Soc Sci Med 1997 Apr; 44 (8): 1081-8.

10. Heath I. Person-centered prevention and health promotion. Int J Integr Care 2010 Jan 29; 10 Suppl: e032.

11. Pinto D, Heleno B, Gallego R, Santos I, Santiago LM, Maria V. Norma Terapêutica da Diabetes Mellitus tipo 2: metformina - uma perspectiva crítica. Acta Med Port 2011 Mar-Abr; 24 (2): 331-8.

\section{ENDEREÇO PARA CORRESPONDÊNCIA}

Mónica Granja

Centro de Saúde Sra. da Hora

R. da Lagoa

4460-352 SRA. HORA

monica.granja@ulsm.min-saude.pt 